\title{
The Effect of Prunus Mume Supplementation on Energy Substrate Levels and Fatigue Induction Factors
}

\author{
II-Young Paik, Woe-Ryong Chang, Yi-Sub Kwak', Su-Youn Cho and Hwa-Eun Jin* \\ Department of Physical Ecucation, Yonsei University, 262 Seongsanno Seodaemnn Gu, Seoul, Korea \\ ${ }^{1}$ Department of Physical Education, Dong-Eui University, 995 Eomgwangno, Busanjin-gu, Busan, Korea
}

Received September 28, 2009 /Accepted October 8, 2009

\begin{abstract}
The purpose of this study is to examine the effect of Prunus mume supplementation on changes of energy substrate (glucose, FFA) and fatigue factors (lactate, ammonia, phosphorous) in the performance of exercise. The subjects of this study were 15 male university students. The exercise test was performed for 30 minutes at $75 \% \mathrm{VO}_{2}$ max on the treadmill and conducted both before and after administering Prunus mume for 6 weeks. Through Prunus mume supplemntation, the accumulation of such fatigue factors as lactate, ammonia, and phosphorous along with concentration of glucuse decreased, but the concentration of FFA increased. From the study, it can be seen that Prunus mume plays a positive role for the use of energy substrates and accumulated fatigue factors.
\end{abstract}

Key words : Prunus mume, lactate, ammonia, phosphorous, glucose, FFA

\section{서 론}

운동수행력 증진과 관련된 연구는 스포츠 과학 분야에서 가장 중요시되는 과제 중의 하나라고 할 수 있으며, 이에 대한 연구는 끓임없이 이루어지고 있다. 그 중 운동생리학 분야에 서는 운동에 따른 피로를 지연시킴으로써 운동수행력을 향상 시킬 수 있는 방법에 대한 연구가 지속적으로 이어지고 있으 며, 그 방법 중 하나로 영향학적 측면의 에너지 보충제 (ergogenic aid) 섭취가 많이 이용되고 있다. 에너지 보충제 투여는 직 · 간접적으로 에너지 기질 동원 및 활용에 긍정적인 효과를 초래하여 피로를 지연시킴과 동시에 운동수행력을 증 진시키는 역할을 하기 때문에 스포츠 현장에서 널리 이용되고 있으며 조금 더 신체에 부담을 주지 않으면서도 운동수행력을 증진시킬 수 있는 에너지 보충제를 찾아내기 위한 노력이 이 뤄지고 있다.

국내의 경우 민간 및 한방요법을 비롯한 전래의학에 바탕 을 두고 생약 및 자연식품으로부터 추출된 물질을 통해서 운 동 시 에너지 보충제의 효과를 거둘 수 있을 것 이라는 가능 성이 제시되어 왔다. 이에 근거하여 인삼[1], 가시오가피[5], 홍삼[4] 등을 대상으로 이러한 성분들의 산소운반능력 및 운 동피로 회복효과에 대한 실제적인 분석이 시도되어 왔다. 최 근 이러한 기존의 성분들과 함께 국내 전래의학에서 널리 알 려진 매실의 에너지 보충제로서의 효과에 대해 연구가 시도 되고 있다[9].

매실은 매화나무의 열매이며 매화나무는 장미과에 속하는

*Corresponding author

Tel : +82-2-546-3209, Fax : +82-2-518-6112

E-mail : jhwaeun@hotmail.com
낙엽활엽교목으로 이 나무의 핵과를 매실이라 한다. 원산지는 중국의 사천성과 호북성의 산간지로 알려져 있으며 한국, 중 국 및 일본 등에 널리 분포되어 있다. 원래 매실은 행매라 하여 신맛이 약한데, 우리나라에 건너온 후 독특한 계절과 풍토의 영향으로 신맛이 강한 산매로 변했다. 이것은 매실의 생명인 구연사의 함유량이 훨씬 많은 좋은 매실로 변한 것이라고 볼 수 있으며 따라서 매실은 한국산이 최고품이라고 알려져 있 다. 매실은 본초강목 신농본초경, 명의별록 등의 각종 한의서 에 만성기침, 하열에 의한 가슴의 열기나 목마름, 오래된 학질, 만성 설사, 치질, 혈변, 혈뇨, 회충에 의한 급성복통이나 구토, 갈고리촌충 구제를 치료한다고 기록되어 있다. 현재까지 매실 의 효능을 과학적으로 검증한 연구는 항산화성, 항혈전, 아질 산염 소거작용, 피로회복, 간기능 개선 효과 등에 관한 것이었 다. 이러한 기전을 바탕으로 매실은 활력유지, 피로회복 등에 효과를 가진 약제로 이용되어 왔다. 특히 강력한 알칼리성에 해당하는 것으로 알려진 매실은 풍부한 citric acid (구연산) 를 중심으로 한 유기산, 무기질 등을 함유함으로서 운동수행 시 체내 신진대사 활성화, 노폐물 제거, 젖산생성 억제, 헤모글 로빈과의 산소친화력 향상 등에 효과가 높다[14]고 알려져 있 어 대사 기능 촉진 및 피로회복 활성화 등에 도움을 줄 수 있을 것으로 기대된다.

이러한 매실의 기능과 관련된 연구로는 장거리 종목의 운동 선수들을 대상으로 혈액 성분 변화에 대한 매실섭취효과가 분석된 바 있으며[13], Park 등[14]은 여자 배드민턴 선수들을 대상으로 동일한 운동강도에서 매실 엑기스 섭취 후 혈중 젖 산농도의 축적 현상이 감소한 것으로 보고한 바 있다. 그리고 $\mathrm{Kim}$ 등[7]은 고온에서의 점증적인 운동 시 매실음료의 섭취시 가 전반적으로 생수음료 섭취시보다 동일 시기에서 낮은 심박 
수를 나타내면서, 올아웃에 이르는 최대 운동지속시간이 유의 하게 높았다고 보고하였다.

이와 같이 많은 연구들에서 운동수행 시 매실섭취에 따른 운동수행력 향상 및 피로 회복에 관한 효과가 입증되었지만 매실의 함량정도와 섭취량의 차이를 보이고 있으며, 또한 대 부분의 실험들이 매실 외의 다른 물질이 함유된 음료를 섭취 하거나, 섭취기간 중에 트레이닝 등의 운동수행이 동시에 이 뤄짐으로써 입증된 효과가 매실 자체만의 효과라고 확신하기 에는 어려움이 있다고 보여진다.

이에 본 연구에서는 6 주간 다른 함유물질의 첨가 없이 매실 추출물만을 섭취하고, 6 주간 특별한 운동처치를 하지 않음으 로써 6주간 매실의 섭취만으로 운동수행 시 피로에 미치는 영향을 알아보고자 한다. 따라서, 본 연구는 6 주간의 매실추출 물 섭취가 에너지 기질 및 피로 물질 변화에 미치는 영향을 알아보는데 그 목적이 있다.

\section{재료 및 방법}

\section{연구 대상}

본 연구는 남자 대학생 15 명을 대상으로 하였으며, 연구 대 상자의 신체적 특성은 Table 1에 나타나 있다.

\section{실험 절차}

본 실험의 절차는 Table 2 와 같다.

\section{매실 추출물 및 위약 투여방법}

투여 전 테스트가 끝난 후, 매실 투여군은 매실추출물을,

Table 1. Physical characteristics of subjects

\begin{tabular}{cccccc}
\hline $\mathrm{N}$ & $\begin{array}{c}\text { Age } \\
(\mathrm{yr})\end{array}$ & $\begin{array}{c}\text { Height } \\
(\mathrm{cm})\end{array}$ & $\begin{array}{c}\text { Weight } \\
(\mathrm{kg})\end{array}$ & $\begin{array}{c}\text { Body fat } \\
(\%)\end{array}$ & $\begin{array}{c}\dot{\mathrm{VO}_{2} \max } \\
(\mathrm{ml} / \mathrm{kg} / \mathrm{min})\end{array}$ \\
\hline 15 & $21.7 \pm 3.1$ & $176.1 \pm 6.6$ & $70.4 \pm 6.0$ & $14.4 \pm 3.3$ & $52.0 \pm 4.6$ \\
\hline
\end{tabular}

Values are mean \pm standard deviation.

Table 2. Procedure of experiment

\begin{tabular}{c}
\hline$\dot{\mathrm{VO}_{2} \text { max test }}$ \\
$\downarrow$ \\
\hline Estimation of $75 \% \dot{\mathrm{VO}}_{2}$ max value \\
$\downarrow$ \\
\hline $75 \% \mathrm{VO}_{2}$ max test $(30 \mathrm{~min})$ \\
\hline$\downarrow$ \\
\hline Prunus mume supplemntation $(6 \mathrm{wk})$ \\
$\downarrow$ \\
\hline $785 \% \dot{\mathrm{VO}}_{2}$ max test $(30 \mathrm{~min})$ \\
\hline
\end{tabular}

위약 투여군은 위약을 6주간 일일 2회 섭취하였다. 매실 구성 성분은 Table 3 과 같다.

\section{최대산소섭취량 $75 \%$ 산정 및 테스트}

최대산소섭취량 $\left(\mathrm{VO}_{2} \mathrm{max}\right)$ 은 가스분석기 (Monographic 社, USA, CPXsystem) 을 이용하여, breath by breath 방식으로 측정하였으며, Bruce protocol을 채택하여 트레드밀 (Quinton 社, USA, Q65) 에서 실시하였다. $75 \% \mathrm{VO}_{2} \max$ 테스트를 위하 여 테스트 전 각 피험자들의 $\mathrm{VO}_{2} \mathrm{max}$ 를 바탕으로 그에 따른 최대산소섭취량의 $75 \%\left(75 \% \mathrm{VO}_{2} \mathrm{max}\right)$ 를 산정하였다. 6 주간 의 매실추출물과 위약 섭취 전과 섭취 후 모두, Bruce protocol 로 운동을 시작하여 프로그램에 미리 설정된 단계별로 운동 강도가 증가되도록 하다가, 각 피험자들의 산소섭취량이 미리 산정해 놓은 $75 \% \mathrm{VO}_{2} \max$ 수준에 도달하게 되면, 이를 유지시 키기 위하여 트레드밀의 protocol을 수동으로 조절하여, 30 분 간 트레드밀 달리기를 실시하였다.

\section{혈액채취 및 분석방법}

혈액 채취는 매실추출물과 위약 섭취전과 섭취 후 $(0$ 주 및 6 주) 에 각각 4 회(안정 시, 종료 시, 회복 30 분, 회복 1 시간) 실시하였다. 채취된 혈액은 2,500 3,000 rpm에서 15 20분간 원심분리하여, 상층액을 얻어 혈중 피로요소(젖산, 암모니아, 무기인산) 과 에너지 기질(글루코스, 유리지방산)을 분석하는 데 사용하였다. 혈중 젖산, 암모니아, 무기인산은 건식 생화학 분석기(Kodak社, USA, EKTACHEM DT60 II)를 사용하여 분 석하였고, 글루코스는 면역분석기(Bayer社 USA, ADVIA 1650 )를 이용하여 enzymatic 검사법을 사용하였다. 그리고 유 리지방산은 자동생화학 분석기(Hitachi社, Japan, Hitachi 7150)를 이용하여 분석하였다.

\section{자료처리}

본 연구에서 얻은 자료는 SPSS 통계 package (v. 12.0)를 이용하여 기술통계량을 산출하였다. 혈중 피로요인 및 에너지 기질 변화 형태 비교는 투여조건과 시기를 독립변인으로 하는 2(투여조건; 매실투여전, 매실투여후) $\times 4$ (시기; 안정 시, 운동종 료, 회복 30 분, 회복 60 분) 요인설계하에 이루어졌으며, 투여조 건과 시기를 반복 측정하는 이원 분산분석법(two-way ANOVA)을 이용하여 분석하였다. 모든 분석에서 유의한 차 이를 보인 부분은 사후검증(Scheffe)을 실시하였으며, 유의수 준은 0.05 로 설정하였다.

\section{결 과}

매실 투여 조건 간, 시기 간 혈장 젖산 농도 변화를 위해 이원변량분석을 실시하였고, 그 결과 매실 투여 조건과 시기 의 상호작용효과와 투여조건의 주효과에서는 유의한 차이가 
Table 3. Component of Prunus mume

\begin{tabular}{|c|c|c|c|c|}
\hline & Material & $\begin{array}{c}\text { Composition rate } \\
(\%)\end{array}$ & $\begin{array}{l}\text { Amount } \\
(\mathrm{mg} / \text { pill })\end{array}$ & $\begin{array}{l}\text { Daily consumption level } \\
(\mathrm{mg} / \text { day })\end{array}$ \\
\hline Chief ingredient & Prunus mume extract (solid 56\%) & 51 & 102 & 3.264 \\
\hline Excipient & corn sugar & 46 & 92 & 2,944 \\
\hline Excipient & pigment & 3 & 6 & 192 \\
\hline \multicolumn{2}{|r|}{ Total } & 100 & 200 & 6,400 \\
\hline
\end{tabular}

나타나지 않았지만, 시기 $[F(3,42)=133.780, p=0.000]$ 의 주 효과 는 유의하게 나타났다. 시기의 사후검증 결과, 운동종료 시 $(M=6.843)$ 가 안정 시 $(M=1.176)$, 회복30분 $(M=2.210)$, 회복60분 $(M=1.216)$ 보다 유의하게 높게 나타났으며 $(p=0.000)$, 또한 회 복 30분 $(M=2.210)$ 이 회복 60 분 $(M=1.216)$ 보다 유의하게 높게 나타났다 $(p=0.000)$. 매실 투여 전과 매실 투여 후를 비교하면, 유의한 차는 나타나지 않았지만 운동 종료, 회복 30 분, 회복 60 분 각각 매실 투여 후가 매실 투여 전에 비해 2.03\%, 5.57\%, $5.95 \%$ 적은 수치를 보여 매실 투여가 피로회복에 긍정적인 영향을 미침을 보였다(Table 4).

매실 투여 조건 간, 시기 간 혈장 암모니아 농도 변화를 위해 이원변량분석을 실시하였고, 그 결과 매실 투여 조건과 시기 의 상호작용효과가 유의하게 나타났다 $[F(3,36)=3.387, p<$ 0.05]. 이에 대한 사후검증으로 매실 투여 조건에 대한 시기별 차이 분석을 위해 일원 변량분석을 실시하였다. 매실 투여 전, 운동 종료시가 가장 높은 수치를 나타냈으며, 안정 시, 회복 30 분, 회복 60 분 보다 유의하게 높게 나타났다 $(p=0.000)$. 매실 투여 후에도 운동 종료시점이 가장 높은 수치를 나타냈으며, 안정시, 회복 30 분, 회복60분 보다 유의하게 높게 나타났다 $(p=0.000)$. 매실 투여 전과 매실 투여 후를 비교하면, 유의한 차는 나타나지 않았지만 운동 종료, 회복 30 분, 회복 60 분 각각 매실 투여 후가 매실 투여 전에 비해 $15.69 \%, 17.23 \%, 19.62 \%$ 적은 수치를 보여 매실 투여가 피로회복에 긍정적인 영향을 미침을 보였다. 또한, 투여조건 $[F(1,12)=21.844, p<0.01]$ 과 시 기 $[F(3,36)=178.256, p=0.000]$ 의 주 효과도 유의하게 나타났다.
투여조건의 사후검증 결과, 매실 투여 전 $(M=67.73)$ 이 매실 투여 후 $(M=55.70)$ 보다 유의하게 높았으며 $(p<0.01)$, 시기의 경우, 운동 종료 시 $(M=104.31)$ 가 안정 시 $(M=48.08)$, 회복 30 분 $(M=48.35)$, 회복 60 분 $(M=46.12)$ 보다 유의하게 높게 나타났다 $(p=0.000)$ (table 4).

매실 투여 조건 간, 시기 간 혈장 무기인산 농도 변화를 위해 이원변량분석을 실시하였고, 그 결과 매실 투여 조건과 시기 의 상호작용효과와 투여조건의 주효과에서는 유의한 차이가 나타나지 않았지만, 시기 $[F(3,30)=73.248, p=0.000]$ 의 주 효과 는 유의하게 나타났다. 시기의 사후검증 결과, 운동 종료 시 $(M=5.068)$ 가 안정 시 $(M=3.714)$, 회복 30 분 $(M=3.905)$, 회복 60 분 $(M=3.627)$ 보다 유의하게 높게 나타났으며 $(p=0.000)$, 또한 회복 30 분 $(M=3.905)$ 이 회복 60 분 $(M=3.627)$ 보다 유의하게 높 게 나타났다 $(p=0.000)$. 매실 투여 전과 매실 투여 후를 비교하 면, 유의한 차는 나타나지 않았지만 운동 종료, 회복 30 분, 회 복 60 분 각각 매실 투여 후가 매실 투여 전에 비해 $3.35 \%$, $3.88 \%, 4.89 \%$ 적은 수치를 보여 매실 투여가 피로회복에 긍정 적인 영향을 미침을 보였다(table 4).

매실 투여 조건 간, 시기 간 혈장 글루코스 농도 변화를 위해 이원변량분석을 실시하였고, 그 결과 매실 투여 조건과 시기 의 상호작용효과, 투여조건과 시기의 주효과에서 유의한 차이 가 나타나지 않았다.

매실 투여 전과 매실 투여 후를 비교하면, 유의한 차는 나타 나지 않았지만 운동 종료, 회복 30 분, 회복 60 분 각각 매실 투여 후가 매실 투여 전에 비해 $2.54 \%, 0.6 \%, 3.11 \%$ 적은 수치

Table 4. Comparison of fatigue factors

\begin{tabular}{lcccc}
\hline & Resting & End of exercise & Recovery 30 min & Recovery 60 min \\
\hline Before supplementation & $1.22 \pm 0.58$ & Lactate $(\mathrm{mmol} / \mathrm{l})$ & $1.25 \pm 0.47$ \\
After supplementation & $1.13 \pm 0.37$ & $6.91 \pm 1.94$ & $2.27 \pm 0.71$ & $1.18 \pm 0.49$ \\
\hline & $6.77 \pm 1.89$ & $2.15 \pm 0.51$ & $51.62 \pm 10.82$ \\
\hline Before supplementation & $51.38 \pm 12.62$ & Ammonia $(\mu \mathrm{mol} / \mathrm{l})$ & $40.62 \pm 9.82$ \\
After supplementation & $44.77 \pm 10.66$ & $114.15 \pm 19.60$ & $53.77 \pm 12.94$ \\
\hline \multicolumn{5}{c}{ Phosphorous $(\mathrm{mmol} / \mathrm{l})$} \\
\hline Before supplementation & $3.69 \pm 0.24$ & $5.15 \pm 0.39$ & $42.92 \pm 11.69$ & $3.72 \pm 0.39$ \\
After supplementation & $3.74 \pm 0.48$ & $4.98 \pm 0.58$ & $3.98 \pm 0.40$ & $3.54 \pm 0.57$ \\
\hline
\end{tabular}

Values are mean \pm standard deviation. 
Table 5. Comparison of energy substrates

\begin{tabular}{llccc}
\hline & Resting & End of exercise & Recovery 30 min & Recovery 60 min \\
\hline Before supplementation & $87.87 \pm 5.64$ & Glucose $(\mathrm{mg} / \mathrm{dl})$ & $90.00 \pm 6.70$ \\
After supplementation & $85.67 \pm 13.58$ & $91.87 \pm 10.91$ & $89.47 \pm 10.62$ & $87.20 \pm 4.69$ \\
\hline & $89.53 \pm 5.85$ & $88.93 \pm 10.24$ & $490.69 \pm 345.56$ \\
\hline Before supplementation & $201.92 \pm 97.95$ & Free fatty acids (uEq/l) & $501.46 \pm 319.65$ \\
\hline After supplementation & $270.46 \pm 149.82$ & $334.31 \pm 148.96$ & $502.15 \pm 294.89$ & $500.15 \pm 344.05$ \\
\hline
\end{tabular}

Values are mean \pm standard deviation.

를 보였다(Table 5).

매실 투여 조건 간, 시기 간 혈장 FFA 농도 변화를 위해 이원변량분석을 실시하였고, 그 결과 매실 투여 조건과 시기 의 상호작용효과와 투여조건의 주효과에서는 유의한 차이가 나타나지 않았지만, 시기 $[F(3,36)=14.9444, p=0.000]$ 의 주 효과 는 유의하게 나타났다. 시기의 사후검증 결과, 안정 시 $(M=236.192)$ 가 회복30분 $(M=501.154)$ 과 회복60분 $(M=496.077)$ 보다 유의하게 낮게 나타났으며 $(p<0.01)$, 운동 종료 시 $(M=390.769)$ 가 안정 시 $(M=236.192)$ 와 회복 30분 $(M=501.154)$ 보다 유의하게 높게 나타났다 $(p<0.01)$. 매실 투여 전과 매실 투여 후를 비교하면, 유의한 차는 나타나지 않았지만 운동 종 료 시 매실 투여 후가 매실 투여 전에 비해 $33.78 \%$ 높은 수치를 보임으로 운동수행 증진을 위한 에너지 기질인 유리지방산에 긍정적인 영향을 미침을 보였다(table 5).

\section{고 찰}

인체는 생명을 유지하기 위해, 그리고 신체활동을 위해 음 식을 섭취하고, 섭취된 음식은 신체내로 흡수되어 에너지를 생성하게 된다. 이러한 에너지를 생성하기 위해 신체 내에서 는 여러 화학적 작용을 거치게 되며, 에너지의 근원이 되는 영양소인 탄수화물, 지방, 단백질은 이러한 화학 작용들 중 citric acid cycle을 거치게 된다. 이 citric acid cycle을 통해 많은 에너지를 생성하게 되는데, citric acid cycle이 원활하게 돌아가는데 필수적인 것이 citric acid이다. 만약 citric acid cycle이 원활하게 돌아가지 않는다면 혈중 젖산이 축적되어 피 로유발의 원인이 될 수 있다.

젖산 생성은 운동시 근육 피로를 유발하는 주요 인자로 간 주되어 오고 있으며[16], 운동으로 인한 근육에서의 젖산 축적 이 $\mathrm{pH}$ 를 감소시켜 피로를 유발시킨다고 알려져 있다[14].

본 연구에서 피로물질인 혈중 젖산 농도는 매실 섭취 전에 비해 매실 섭취 후 유의한 차는 나타나지 않았지만 낮은 수치 를 보였다. 이러한 결과는 $\mathrm{Kim}$ 등[8]이 12주간의 매실음료를 섭취시킨 그룹이 섭취하지 않은 그룹에 비해 유의하게 낮은 혈중 젖산 농도를 보여 피로회복에 효과적임을 입증한 연구와 $\operatorname{Min}$ 등[11]이 매실음료와 스포츠음료를 비교해본 결과, 혈중
젖산 농도가 유의한 차는 나타나지 않았지만 스포츠음료보다 더 낮은 수치를 나타내었다는 연구와 일치하는 결과였다. 이 것은 매실 중에 포함된 citric acid가 에너지 생성 과정에서 젖산의 과잉생성을 억제하고 탄산가스를 물로 분해 시켜 체외 로 배설시킴으로 조기에 피로물질을 없앤 것이라 할 수 있다. 또한, 매실에 다량 함유된 citric acid가 운동이 진행됨에 따라 산성화되어 가는 인체를 약알칼리성으로 유지할 수 있게 한 것뿐만 아니라, 매실이 운동 후 갈증을 감소시킨다는 효능이 있는데, 운동 시 발생하는 갈증을 감소시켜 에너지대사를 촉 진시키는 동시에 젖산의 생성을 억제하여 피로를 회복시켜 새로운 에너지 생성을 더한 것으로 보인다.

근육에서의 피로를 유발시키는 또 다른 인자인 암모니아는 젖산의 생성을 유발하고 글리코겐의 빠른 저하를 가져와 근육 의 피로를 유발시킨다고 알려져 있다. 본 연구에서 혈중 암모 니아 농도는 매실 투여 전이 매실 투여 후보다 유의하게 높게 나타났다. 이는 매실 투여 전이 매실 투여 후에 비해 근육 세포 막의 표면에 작용하는 전기적 자극을 변화시켜 근육의 장력 발생을 저하시키며, 그 결과 해당 작용에 있어서 주요 효소인 Phosphofructokinase (PFK)의 활동을 자극하고 citric acid cycle과 gluconeogenesis를 저해하여 mitochondria 산화를 제한 [16]한 것이라 할 수 있다. 이로 인해 젖산의 축적을 가중시키 고 근육에 저장되어 있는 글리코겐 고갈을 가속화시켰고, $\mathrm{ATP}$ 재생성을 손상시켜 AMP 축적을 가져와 암모니아 생성 을 일으켰으며[15], 그 결과 피로 유발과 관련이 있는 산성화가 시작될 가능성을 제공했다고 본다. 반면 매실이 인체의 산성 화를 억제함으로써 $\mathrm{pH}$ 감소의 시작을 더디게 하여 속근 섬유 의 동원 비율보다 지근 섬유가 운동에 관여하게 되어 암모니 아의 적은 축적을 가져온 것 같으며, 결과적으로 혈중 젖산 농도의 적은 생성을 가져온 것이라 생각된다.

무기인산은 힘의 소멸과 연관이 있다고 알려져 있으며, 힘 발현은 무기인산의 농도와 밀접한 연관이 있다. 초기의 피로 관련 연구가 근육 피로의 원인을 산성화에 초점을 맞추었지 만, 최근의 연구들은 세포내 무기인산 $(\mathrm{Pi})$ 축적이 피로를 이끈 다는 것에 주의를 기울이고 있다[14].

본 연구에서 매실 투여 전에 비해 매실 투여 후에 유의한 차는 없었지만 적은 혈중 무기인산 농도를 나타냈다. 이는 매 
실 투여로 인해 신체의 산성화가 억제되어 ATP 가수분해를 더디게 하여 무기인산의 적은 농도를 나타낸 것이라 할 수 있다. ATP 가수분해가 증가하게 되면 근육의 힘 생성을 위한 actin과 myosin의 cross-bridge를 위한 강력한 결합을 감소시 켜 힘 생성을 저하시키게 되며, 또한 근육의 장력 발생에 영향 을 미치게 된다. 따라서 매실이 신체의 산성화를 더디게 함으 로써 ATP의 가수분해를 감소시켜 근수축 시 필수과정인 액틴 과 마이오신의 cross-bridge의 강력한 결합에 영향을 미쳐 적 은 혈중 무기인산 농도를 나타냈다고 할 수 있다.

운동 시 탄수화물과 지방은 중요한 에너지 기질이며, 근육 의 글리코겐 분해와 혈중 글루코스 섭취 등이 전반적인 탄수 화물 대사에 영향을 미치고, 지방 세포로부터 혈중으로 방출 되어 순환하는 유리지방산(FFA)이 가장 중요한 에너지원으로 알려져 있다.

운동 시 발생하는 피로는 글리코겐 고갈과 연관되어 있지 만, 이러한 연관성의 명확한 생화학적 기전은 분명하지 않다 [14]. Sahlin 등[15]은 운동 시 피로는 AMP 탈아미노 작용의 증가에 의해 나타나는 에너지 결핍에 의해 설명되어질 수 있 음을 발견했고, citric acid cycle 중간물들의 감소가 citric acid cycle의 흐름을 손상시켜 피로를 유발시키는 유산소 에너지들 을 감소시킨다고 보고했다.

본 연구에서 매실 투여 후가 투여 전보다 글루코스 농도는 낮게 나타난 반면, 유리지방산 농도는 높게 나타났다. 앞서 언급한 세 가지 피로물질인 혈중 젖산, 암모니아, 무기인산의 농도는 매실 투여 전에 비해 매실 투여 후에 적은 농도를 나타 냈다. 이는 매실에 포함된 citric acid가 운동으로 인해 발생할 수 있는 신체의 산성화를 약알칼리로 유지시켜줌으로 피로물 질들의 적은 축적을 가져왔다고 할 수 있다. 매실 투여로 인해 혈중 암모니아 축적이 감소되어 글리코겐 고갈을 지연시켰으 며, 그 결과 혈중 젖산 농도의 감소를 유발한 것으로 보인다. 젖산대사의 증가는 글루코스 생성을 억제하여 혈중 수치를 감소시키는데, 매실 투여로 인해 젖산 수치가 감소되어 그 결 과 글루코스 생성이 증가된 것이라 할 수 있다. 무기인산의 축적은 phosphorylase의 활성화에 영향을 주고 적은 글리코 겐의 감소를 유도하여, 장기적으로는 에너지원의 보존에 기여 한 것으로 보인다. 매실이 운동으로 인한 $\mathrm{pH}$ 감소를 억제함으 로서 빠른 탄수화물 고갈의 저해와 피로 유발을 방지한 것으 로 보인다.

결과적으로, 피로물질 축적의 감소는 피로를 유발한다고 알 려진 글리코겐의 고갈을 더디게 한다고 알려져 있는데, 본 연 구에서도 매실투여로 인해 피로물질의 생성이 낮아져 더 많은 유리지방산을 사용하는 반면 글루코스 사용의 감소를 가져왔 다고 할 수 있다. 또한, 글리코겐 결핍이 citric acid cycle 중간 물들의 고갈을 통한 피로 발전과 연관되어질 수 있는데, 매실 에 다량 함유된 citric acid로 인해 글리코겐 고갈을 어느 정도 지연시킨 것이라 생각된다.

\section{References}

1. Bahrke, M. S., W. P. Morgan, and A. Stegner. 2009. Is ginseng an ergogenic aid? International Journal of Sport Nutrition and Exercise Metabolism 19, 298-322.

2. Bowtell, J. L., S. Narwood, M. Bruce, D. ConstantinTeodosiu, and P. L. Greenhaff. 2007. Tricarboxylic acid cycle intermediate pool size. Sports Medicine 37, 1071-1088.

3. Choi, K. W. 1992. The effect of Pruns mume's extract on lactate recovery rate after aerobic exercise. The Association of Korean Oriental Medicine 31, 2327-2333.

4. Fulder, S., C. Hallstrom, and M. Caruthers. 1980. The effect of ginseng on the performance of nurses on night duty. Korea Ginseng Research Institute 81-85.

5. Gaffney, B. T., H. M. Hugel, and P. A. Rich. 2001. The effects of Eleutherococcus senticosus and Panax ginseng on steroidal hormone indices of stress and lymphocyte subset numbers in endurance athletes. Life Sciences 17, 431-442.

6. Glaister, M. 2005. Multiple sprint work. Physiological responses, mechanisms of fatigue and the influence of aerobic fitness. The Journal of Sports Medicine 35, 757-777.

7. Kim, K. J. and J. H. Bae. 1999. Effects of sports drink including the extract from Pruns mume on the changes of respiratory variables, heart rate, and blood lactate concentration in submaximal exercise. The Journal of East Asian of Dietary Life 9. 177-187.

8. Kim, K. J. and J. H. Bae. 2000. Effects of sports drink including the extract from Pruns mume on the change of physiological variables related to blood gas and water metabolism during submaximal exercise. Korean Journal of Sports Medicine 18, 48-58.

9. Kim, S., S. H. Park, H. N. Lee, and T. S. Park. 2008. Prunus mume extract ameliorates exercise-induced fatigue in trained rats. Journal of Medicinal Food 11, 460-468.

10. Kristensen, M., J. Albertsen, M. Rentsch, and C. Juel. 2005. Lactate and force production in skeletal muscle. The Journal of Physiology 562, 521-526.

11. Min, B. I., C. W. Bae, and Y. S. Choi. 2003. Effect of Ion beverage substitution to Maesil-beverage on the Exercise Performance. Korea Sports Research 14, 868-878.

12. Mutch, B. J. and E. W. Banister. 1983. Ammonia metabolism in exercise and fatigue: a review. Medicine and Science in Sports and Exercise 15, 41-50.

13. Park, S. G. and H. D. Kim. 1988. The influence of Mae Sle extract on blood components of a long-distance player. Korean Journal of Sports Medicine 6, 26-31.

14. Park, S. G. 1990. Effect of Maesil extracts on the blood components of women badminton players. Korean Journal of Sports Medicine 8, 40-43.

15. Sahlin, K., A. Katz, and S. Broberg. 1990. Tricarboxylic acid cycle intermediates in human muscle during prolonged exercise. American Journal of Physiology 259, C834-C841.

16. Sola-Penna, M. 2008. Metabolic regulation by lactate. IUBMB Life 60, 605-608. 


\section{초록 : 매실 추출물 섭취가 에너지기질 및 피로물질 변화에 미치는 영향}

백일영 · 장외룡 · 곽이섭 ${ }^{1}$ 조수연 · 진화은*

(연세대학교 체육교육학과, ${ }^{1}$ 동의대학교 체육학과)

이상의 연구결과를 종합해볼 때, 매실투여로 인해 젖산, 암모니아, 무기인산과 같은 피로물질의 축적은 감소되 고, 혈중 글루코스 수치는 감소한 반면 유리지방산 농도는 증가했다. 피로는 일반적으로 피로물질의 축적과 에너 지기질의 고갈로 인해 발생한다. 매실에 포함되어 있는 citric acid는 피로회복의 역할로 가장 널리 알려져 있으며, 본 연구를 통해 매실 섭취가 운동이 진행됨에 따라 산성화되어 가는 인체를 약알칼리로 유지하게 하여 $\mathrm{pH}$ 감소 를 억제함으로 혈중 피로물질들의 낮은 농도를 가져온 것으로 보인다. 또한 글리코겐 결핍이 citric acid cycle 중간물들의 고갈을 통한 피로 발전과 연관되어질 수 있는데, 매실에 함유된 citric acid가 글리코겐 고갈을 지연시 키고 반면에 유리지방산을 많이 사용하게 함으로 피로물질의 적은 축적을 가져온 것으로 생각된다. 따라서 매실 이 운동 시 발생하는 에너지 기질 이용과 혈중 피로물질들의 축적에 긍정적인 영향을 미침을 알 수 있었다. 본 연구는 매실이 운동에 미치는 영향을 검증하기 위해 매실만을 투여하였으며, 매실 섭취가 운동에 긍정적인 영향 을 미친다는 결론을 얻었으므로 운동 시 다양하게 적용할 수 있으리라 기대할 수 있다. 그러나 본 연구에서 사용 한 매실투여량과 다른 매실투여 관련 연구들 및 시중에서 판매되는 매실음료의 함량 사이에는 차이가 발생한다. 이에 매실의 최적의 효과를 위한 투여량이 결정될 필요가 있으며 이와 관련된 연구가 진행되어야 할 것이다. 또 한, 매실이 에르고제닉 에이드로써 활용되기 위해서 다양한 운동 및 훈련 조건에서의 과학적 자료가 확립될 필요 가 있다고 본다. 